\title{
Effect of Kaolin Clay and Alumina on Thermal Performance and Char Morphology of Intumescent fire retardant coating
}

\author{
Hammad aziz $^{1, \mathrm{a}}$, Faiz Ahmad ${ }^{1, \mathrm{~b}}$, Puteri Seri Melor Binti Megat Yusoff ${ }^{1, \mathrm{c}}$ and M. Zia-ul-Mustafa ${ }^{1, \mathrm{~d}}$ \\ ${ }^{1}$ Department of mechanical Engineering, Universiti Teknologi PETRONAS, Bandar Seri Iskandar, \\ Tronoh 31750, Malaysia
}

\begin{abstract}
Intumescent fire retardant coating (IFRC) have been developed by using ammonium polyphosphate, expandable graphite, melamine, boric acid, kaolin clay and alumina as fillers bound together with epoxy resin and cured with the help of curing agent. Five different formulations were developed with and without using fillers. Cured samples were burned in furnace at $500^{\circ} \mathrm{C}$ for $2 \mathrm{~h}$ for char expansion. Bunsen burner test was performed for $1 \mathrm{~h}$ using UL-94 vertical burning test to investigate the thermal performance of IFRC. The resultant char obtained after burning of coated samples were characterized by using field emission scanning electron microscopy for char morphology. Char composition was analyzed by using fourier transform infrared spectroscopy. Thermogravimetric analysis was carried out to investigate the residual weight of coating. Results showed that formulation with 0.5 weight $\%$ of kaolin clay and 0.5 weight $\%$ of alumina provide best thermal performance, uniform and multi-porous char structure with high anti-oxidation property.
\end{abstract}

\section{Introduction}

Steel is an important part of any construction industry like buildings, bridges, cars, off shore and onshore structures etc $[1,2]$. At elevated temperature, the mechanical properties and load bearing ability of steel declines. In case of fire, the temperature of unprotected steel reaches to critical temperature within no time and within 45 min whole of the structure ruins causing loss of lives, assets etc. In order to protect steel against fire, two types of fire protection system such as active and passive fire protection system have been used.

Intumescent originates from the word "intumescence" means swelling of certain substance in case of fire. It is one of the easiest and oldest method of protecting structural steel against fire and presents several advantages like it does not modify the intrinsic properties of the material [2], does not alter the performance of substrate and it can be applied on several materials like wood $[3,4]$, polymer [5] and metals [6] etc. It contains three basic ingredients such as acid source, carbon source and blowing agent [7]. Intumescent fire retardant coating (IFRC) forms on heating an expanded multi-cellular char layer having thickness better than the original thickness of coating which acts as a thermal barrier, protects the substrate from fire and mass loss form substrate to the fire. Conventionally coating was based on ammonium polyphosphate (APP) as acid source, pentaerythritol (PER) as carbon source and

\footnotetext{
${ }^{a}$ Corresponding author : engr.hammad.aziz03@gmail.com
}

This is an Open Access article distributed under the terms of the Creative Commons Attribution License 2.0, which permits unrestricted use, distribution, and reproduction in any medium, provided the original work is properly cited. 
melamine (MEL) as blowing agent. The performance of coating was not adequate and char was easily oxidized at high temperature $[8,9]$.

Kaolin clay had better intumescence and by using $5 \%$ as filler the thermal efficiency of IFRC was enhanced [10]. When alumina was used as filler the residual weight was significantly increased and it improved the thermal efficiency of IFRC [11]. Flame retardancy of polypropylene in intumescent system with ammonium polyphosphate was decreased by using alumina filler [5]. However, the combined effect of both alumina and kaolin clay fillers with expandable graphite was not investigated in intumescent system yet. In this research work, expandable graphite was used as carbon source and combine effect of these two fillers towards thermal efficiency, char morphology and anti-oxidation of IFRC was studied.

\section{Materials}

APP, EG and MEL were used as acid source, carbon source and blowing agent respectively. BA used as an additive. Kaolin clay and alumina were used as fillers. Bisphenol A with polyamide amine acts as curing agent. Four formulations were prepared i.e. IF1, IF2, IF3, IF4 and IF5 as shown in Table 1.

Table 1. Preparation of intumescent coating formulations

\begin{tabular}{|c|c|c|c|c|c|c|c|}
\hline Formulations & APP & EG & MEL & BA & Kaolin clay & Alumina & Curing agent \\
\hline IF1 & 11.14 & 5.57 & 5.57 & 11.14 & 0.00 & 0.00 & 66.58 \\
\hline IF2 & 11.14 & 11.14 & 5.57 & 5.57 & 0.00 & 0.00 & 66.58 \\
\hline IF3 & 11.14 & 5.57 & 5.57 & 11.14 & 0.50 & 0.50 & 65.58 \\
\hline IF4 & 11.14 & 5.57 & 5.57 & 11.14 & 1.00 & 1.00 & 64.58 \\
\hline IF5 & 11.14 & 5.57 & 5.57 & 11.14 & 1.50 & 1.50 & 63.58 \\
\hline
\end{tabular}

\section{Preparation of intumescent fire retardant coating}

First of all APP, BA, MEL and fillers were ground using grinder for 1 min. After that epoxy, all ground material and EG were mixed using shear mixture for $20 \mathrm{~min}$ at $40 \mathrm{rpm}$. Adding hardener and mixed it for further $10 \mathrm{~min}$ at same rpm until uniform dispersion achieved. Formulations were then coated on steel substrate using brush and placed at room temperature for curing.

\section{Results and Discussions}

\subsection{Furnace test}

Furnace test was performed to investigate the char expansion using CARBOLITE ELECTRIC FURNACE. The samples were left in furnace for $2 \mathrm{~h}$ and divided into three segments. In first the sample were heated to $500^{\circ} \mathrm{C}$ with heating rate $20^{\circ} \mathrm{C} / \mathrm{min}$. Second segment is the dwell time of $1 \mathrm{~h}$ at $500^{\circ} \mathrm{C}$ to ensure complete burning of coating. Last segment is the cooling of samples from $500^{\circ} \mathrm{C}$ to room temperature in $35 \mathrm{~min}$. Physical structure of char was also investigated besides char expansion. IF1 which was without filler have good expansion but the char contained cracks and poor adhesion with substrate. IF2 has the highest expansion due to high wt. \% of EG but the char was loose and fragile. In order to improve the char characteristics, fillers were added. By adding fillers (IF3) the expansion was better as compared to IF1 as shown in fig 1(a). The physical structure of char was uniform, exhibited good adhesion with substrate and also good cohesion among the char. IF4 and IF5 have good expansion as compared to IF1 but the cracks were formed inside the char. Good expansion provides better thermal insulation and anti-oxidation of char at higher temperature. Physical structure was also important for better thermal insulation apart from char expansion. If the coating has good expansion but cracks were formed inside the char then it will lead to the heat of flame to penetrate inside the char to the substrate resulted in poor char integrity at high temperature. 


\subsection{Bunsen burner test}

Heat insulation test was performed by using Bunsen burner test. Three K type thermocouples were attached to the backside of the steel substrate and other end connected to the ANARITSU 800AM DATA LOGGER. The temperature of flame used was more than $1100^{\circ} \mathrm{C}$. Backside temperature of substrate was recorded after every $1 \mathrm{~min}$. It was observed that the backside temperature of bare steel plate reaches to more then $450^{\circ} \mathrm{C}$ within $5 \mathrm{~min}$. In order to protect steel substrate IFRC was used. The mean backside substrate temperature of IF1 which was without filler was reached to $267^{\circ} \mathrm{C}$ after $1 \mathrm{~h}$ and for IF2 was $284^{\circ} \mathrm{C}$. When the coating was modified with fillers, the thermal efficiency increased significantly with the final backside substrate temperature after $1 \mathrm{~h}$ was only $105.5^{\circ} \mathrm{C}$ for IF3. The final backside substrate temperature after $1 \mathrm{~h}$ for IF4 and IF5 were $154.7^{\circ} \mathrm{C}$ and $160.1^{\circ} \mathrm{C}$ respectively as shown in fig. 1(b). IF3 had better thermal insulation and char expansion as compared to other formulations studied.
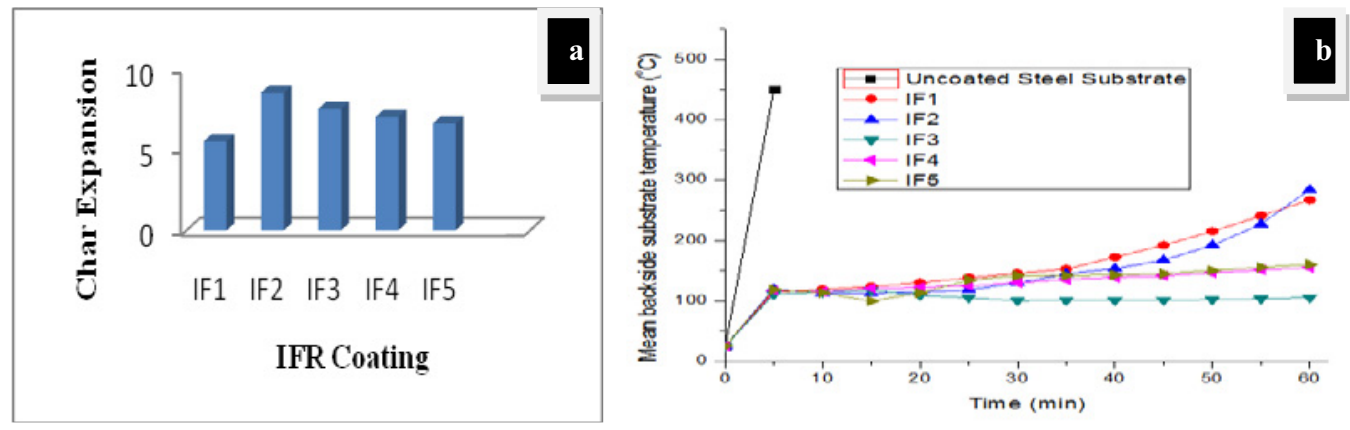

Figure.1. (a) Char expansion, (b) Backside steel temperature Vs time

\subsection{Field emission scanning electron microscopy (FESEM)}

The exfoliated char obtained after fire test was characterized by using SUPRA 55VP manufactured by Carl Zeiss AG, Germany for char morphology and microstructure. The microstructure for IF1, IF2 and IF3 is shown in fig 2(a, b, c). IF1 which was without filler has uneven and non-uniform structure. The microstructure of IF2 has big hole size which aids in transference of heat from these big holes to the metallic substrate [12]. IF3 showed dense and multi-porous char structure with even cell size distribution and has best thermal insulation among other formulations. The average cell size is $9.28 \mu \mathrm{m}$ which helps in reducing the heat of flame to penetrate inside to the substrate. The multi-porous char structure is desirable because it blocks the heat transference to the substrate as shown in fig 2(b). Cell size diameter must be within $50 \mu \mathrm{m}$ in order to achieve good thermal insulation of char [13].
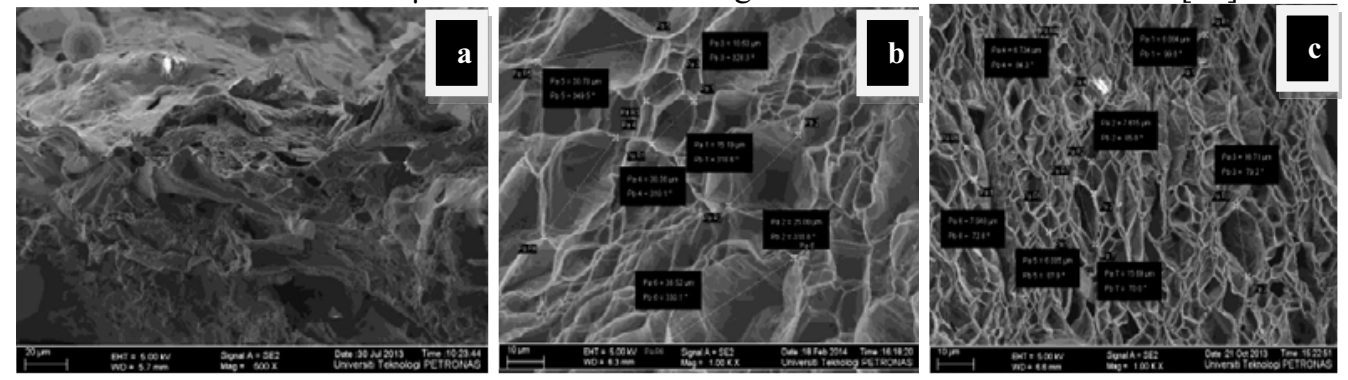

Figure2. Microstructure of char, (a) IF1, (b) IF2, (c) IF3 


\subsection{Fourier transform infrared spectroscopy (FTIR)}

FTIR was carried out by using Spectrum One manufactured by Perkin Elmer Inc. Sample was prepared by mixing the char sample with $\mathrm{KBr}$ and characterized for chemical functional groups present in the char. IF3 have highest thermal insulation as compared to other formulations. The bending peak at $3431.44 \mathrm{~cm}^{-1}$ represents $\mathrm{O}-\mathrm{H}$ group due to epoxy. Bending vibration peak at $2359.95 \mathrm{~cm}^{-1}$ represents nitrile group C-N. Melamine is used as blowing agent which contained amide group and at the decomposition temperature it dehydrates to nitrile group [14]. Bending peak at $1630.62 \mathrm{~cm}^{-1}$ represents amino group $\mathrm{NH}_{2}$. Region $1400-800 \mathrm{~cm}^{-1}$ represents phosphate P-O-P and it is present at the bending vibration peaks at $1192.71 \mathrm{~cm}^{-1}$ and $1085.79 \mathrm{~cm}^{-1}$. Bending peak at $624.99 \mathrm{~cm}^{-1}$ represents the B-O-P group. Boric acid dehydrated into boron oxide and boron oxide further reacted with the decomposition products of APP to from boron phosphate and it is represented by B-O-P group. The bending peak at $546.48 \mathrm{~cm}^{-1}$ represents the Al-O group as alumina is used as filler during the preparation of IFRC as shown in fig. 3(b).

\subsection{Thermogravimetric analysis (TGA)}

Thermo gravimetric analysis was carried out by using Pyris 1 TGA manufactured by Perkin Elmer. The heating rate was $10^{\circ} \mathrm{C} / \mathrm{min}$ in the range of $30-800^{\circ} \mathrm{C}$ under $\mathrm{N}_{2}$ atmosphere. TGA curves have four decomposition stages. In the first stage from $0-200^{\circ} \mathrm{C}, 15 \%$ of weight loss occurred mainly due to decomposition of volatilized solvent and some molecules of epoxy resin. Also, boric acid dehydrated to metaboric acid in the range of $100-140^{\circ} \mathrm{C}$ and further metaboric acid dehydrated to boron oxide at $140-180^{\circ} \mathrm{C}$ [2] which is a hard intumescence glass. During second stage $200-350^{\circ} \mathrm{C}, 12$ weight loss occurred. APP started to decompose by releasing ammonia and water vapors. EG was decomposed above $200^{\circ} \mathrm{C}$ and released carbon dioxide. MEL was decomposed to release ammonia which blows the charring layer formed by the chemical reaction between the decomposition products of APP, EG and boric acid. In third stage, $350-550^{\circ} \mathrm{C}, 20-25 \%$ weight losses occurred due to the decomposition of APP and converted into polyphosphoric and metaphosphoric acid. Boron phosphate was formed due to chemical reaction occurred between the decomposition products of APP and boric acid, which is a thermally stable compound and decompose above $1200^{\circ} \mathrm{C}$. In fourth stage, $550-800^{\circ} \mathrm{C}$, non-combusted residual char layer was formed which provides thermal insulation and also intumescence layer shrink in this stage and degrade slowly. The final residual weight at $800^{\circ} \mathrm{C}$ for IF1, IF2 and IF3 was 29.007 , 25.387 and 35.186 wt. \% respectively as shown in fig. 3(a). By adding the fillers, residual weight increased significantly besides thermal insulation. Higher residual weight enhanced anti-oxidation property of coating so that the char will sustain higher temperature for longer time.
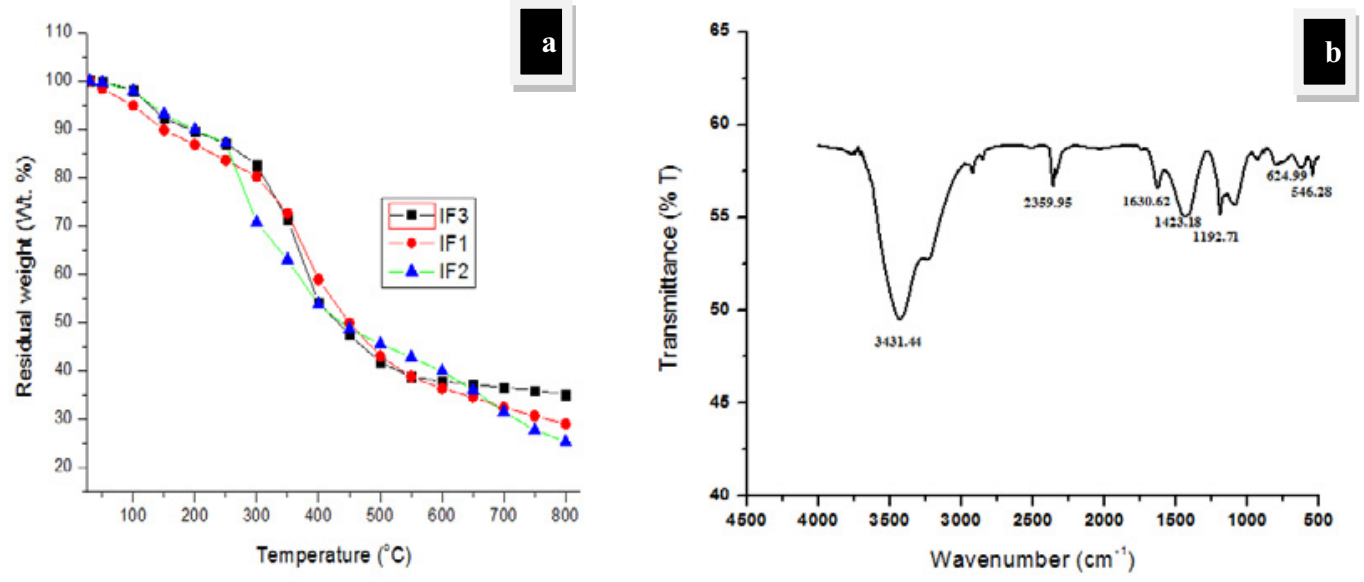

Figure 3. (a) TGA curves for IF1, IF2 and IF3, (b) FTIR spectra of IF3 


\section{Conclusion}

This paper described the thermal efficiency of alumina and kaolin clay filler based IFRC towards protecting unloaded structural steel. Multi-cellular char was formed due to interaction among APP, EG and MEL. Results showed that by using small quantity of fillers; physically good char structure with uniform expansion was achieved as illustrated by furnace test and it was stable for $2 \mathrm{~h}$. The backside temperature of steel substrate after $1 \mathrm{~h}$ was only $105.5^{\circ} \mathrm{C}$ and has very good thermal insulation property. FESEM showed dense and multi-porous char structure with less cell size diameter. FTIR represents the functional group B-O-P, P-O-P and Al-O. Higher residual weight was achieved i.e. $35.186 \mathrm{wt}$ \% $\%$ by adding small amount of fillers providing better anti-oxidation property. By increasing the wt. \% of EG i.e. IF2, highest char expansion achieved compared to other formulations studied but thermal efficiency and residual weight decreased. It is concluded that only char expansion is not important other factors like thermal efficiency, residual weight and microstructure are also important. By adding fillers, thermal insulation and anti-oxidation property enhanced up to certain extent of fillers.

\section{Acknowledgement}

The author acknowledges the facilities and materials provided by Universiti Teknologi PETRONAS, Malaysia.

\section{References}

1. M. C. Yew and N. Ramli Sulong, Materials \& Design, 34, pp. 719-724, (2012)

2. M. Jimenez, S. Duquesne, and S. Bourbigot, Thermochimica acta, 449, pp. 16-26, (2006)

3. J.-w. Gu, G.-c. Zhang, S.-1. Dong, Q.-y. Zhang, and J. Kong, Surface and coatings Technology, vol. 201, pp. 7835-7841, (2007)

4. F. Wang, Z. Zhang, Q. Wang and J. Tang, Frontiers of Forestry in China, 3, pp. 487-492, (2008)

5. X. Almeras, M Le Bras, P. Hornsby, S. Bourbigot, G. Marosi, S. Keszei and F Poutch, Polymer Degradation and Stability, vol. 82, pp. 325-331, (2003)

6. S. Duquesne, S. Magnet, C. Jama and R. Delobel, vol. 180, pp. 302-307, (2004)

7. G. Li, G. Liang, T. He, Q. Yang, and X. Song, Polymer Degradation and Stability, 92, pp. 569$579,(2007)$

8. C.-S. Chou, S.-H. Lin and C.-I. Wang, Advanced Powder Technology, 20, pp. 169-176, (2009)

9. G. Li, J. Yang, T. He, Y. Wu and G. Liang, Surface and coatings Technology, 202, pp. 3121-3128, (2008)

10. S. Ullah, F. Ahmad and P. Megat-Yusoff, Journal of Applied Sciences, 11, pp. 3645-3649 (2011)

11. W. F. Mohamad, F. Ahmad and S. Ullah, Asian Journal of Scientific Research, 6, pp. 263-271, (2013)

12. G. Wang and J. Yang, Progress in Organic Coatings, 70, pp. 150-156, (2011)

13. Z. Wang, E. Han and W. Ke, Progress in Organic Coatings, 53, pp. 29-37, (2005)

14. S. Levchik, L. Costa, G. Camino, sPolymer degradation and stability, 43, pp. 43-54, (1994) 